\title{
Non-metaphorical Objects as Alternate Means of Literary Communication in Selected Plays of A. B. Chukuezi
}

\author{
Chioma M. Akaeze \\ Department of Linguistics, Igbo and Other Nigerian Languages, University of Nigeria, Nsukka, Nigeria \\ Chinedu C. Ezebube \\ Department of Linguistics, Igbo and Other Nigerian Languages, University of Nigeria, Nsukka, Nigeria \\ Ogechukwu F. U. Chukwuneke \\ Department of Linguistics, Igbo and Other Nigerian Languages, University of Nigeria, Nsukka, Nigeria \\ Chioma J. Ikechukwu-Ibe \\ Department of Linguistics, Igbo and Other Nigerian Languages, University of Nigeria, Nsukka, Nigeria
}

\begin{abstract}
Emphasis on effective communication has become the concern of many literary scholars. The need to explore where the burden of communication lies in the literary arts resounds among literary critics and beyond. The study sets out to examine how ordinary intentional dramatic objects in selected Igbo plays of A. B. Chukuezi; Udo Ka Mma, Aku Fechaa and Akwa Nwa are utilised to influence and communicate the intents of the drama texts to the audience. The theoretical framework is based on the viewpoint of theatre semiotics. The belief of theatre semiotics is that every part of a play is relevant in the actualisation of the complex whole called the text. The findings suggest that dramatic objects are not mere symbols for stage beautification, but are objects that can connect a text to its audience. They can also illuminate and illustrate the content and context of a text; as well as develop and extend a storyline.
\end{abstract}

Index Terms-communication, dramatic objects, non-metaphorical, Chukuezi, Igbo plays

\section{INTRODUCTION}

Communication is a crucial aspect of literature. It has been noted that the gap or lack of understanding between the writer and his audience has been the bane of modern literary world (Jeyifo, 1981). The question of information mobility or communication is a challenge that cannot be easily overlooked in the literary world. Communication could simply be seen as the exchange of information, ideas and feelings. In a literary work such as drama, communication goes beyond the spoken or written language (Nwaozuzu, 2007). So many dramatic or theatrical elements such as theatrical objects are constantly working together to project literary communication. This study centres mainly on the communicative relevance of theatrical objects or property in selected Igbo plays of Anelechi B. Chukuezi, who was the first playwright to produce an Igbo drama text.

Many literary critics pay little or no heed to the essential roles of physical theatrical objects (otherwise known as hand props) in the explication of a writer's intents and purposes. Much of the attentions of most critics go to the spoken or written language of a writer. These written or spoken language forms of the writer are non physical objects or symbols. They cannot be physically held or touched as hand props. Brook (1990) asks "if there is another means of communication that is as effective as the language of words?" (p.55). Nwaozuzu $(2007$, p.44) attempts a response to this question by claiming that there is the language of the physical symbols used for communication in dramatic literature. The theatrical object or property is one of the dramatic elements that are vulnerable to misinterpretation. Its intention on the stage is often disputed. When a dramatic object or property is read from the script or appears on the stage, people from different cultures tend to give different interpretations to such an object or property. Dramatic objects are very important. Rasmus (2018) notes that a narrative revolves around props, and a narrative cannot work without props. He further notes that a prop can be a character itself or the title of the literary work. So, more studies on theatrical objects or property (prop) become pertinent so as to explore possible ways of interpreting the intents of these dramatic elements. The history of dramatic prop dates back to the renaissance period. It was at a time when small acting troupes travelled to Europe for performances. Many of the performers provided their own costumes. However, special items like stage weapons, furniture, or other hand held devices were seen as company property. The term, 'company property' was eventually shortened to prop. In recent times, the term is used to describe an object used in a stage play and similar entertainments to further the action in that play. Sofer (2003) defines theatrical property as the stage objects 
or physical literary symbols that can combine image with a concept in the theatre. The implication of this definition is that the term, 'theatrical property' could be used interchangeably with the terms; 'stage objects, theatrical objects, or theatrical symbols' (Sofer, 2003 \& Nwaozuzu, 2007).

Theatrical symbols or objects have been classified into subcategories. According to Nwaozuzu (2007, p.45), there are 'Dramatic Non-Intentional Objects' and 'Dramatic Intentional Objects.' The Dramatic Non-Intentional Objects (DNIO) are mere objects or symbols on the stage that do not contribute anything to the plot or mood of the play. Unlike DNIO, the Dramatic Intentional Objects (DIO) contribute to the development of the plot, theme, and mood of the play. In other words, they appear on the stage intentionally because they are used to achieve one thing or the other. Nwaozuzu (2007, p.45) further categorises DIO into two: 'Metaphorised Intentional Objects' (MIO) and the 'Non-Metaphorised Intentional Objects' (NMIO). The above author explains that a metaphorised intentional object exhibits a dual character. Such an object is not what its reality on stage urges the audience to believe it is. There is usually an extension of thought attached to it. However, the non-metophorised intentional objects of a play are ordinary symbols employed by a writer merely to further his plot, highlight his theme, or create mood. The non-metaphorised dramatic object usually has one identity. It is not subjected to different deep semantic implications. They represent the reality of the object they stand for.

Going by this classification, this study sets out mainly to look at the "Non-metaphorised intentional dramatic objects/symbols in selected plays of A. B. Chukuezi namely; Udo ka mma (1974), Akwa nwa (1979) and Aku fechaa (1980). These texts are selected for this study because to the best of the researchers' knowledge, no research has been carried out on them especially as it concerns dramatic symbols or objects used in the plays. Nwaozuzu (2007) observes that stage props are likely to project effective meaning (communication) in a play. So, studies on stage property of Igbo literary works as the present study seeks to achieve will likely enhance the familiarity and appreciation of Igbo literary texts as works of drama. Again, studying the dramatic objects used in these Igbo plays or any other Igbo play can possibly give a clearer picture of the aesthetic and communicative values of such dramatic objects in drama. Another observation that has been made by Honzl (1976) is that audience ability to read symbols add an extra dimension of complexity to theatre. Hence, a major objective of this study is to analyze the place of non-metaphorised intentional objects in the selected Igbo plays. That is, how comprehensive and effective they are in the development of the story plots; and in the illumination of the themes, mood and characters in the plays. It also aims to look at the possible relationship between the dramatic objects and other elements of the plays. To explain this objective further, the study sets out to find out if the non-metaphorised intentional objects in the plays under study are actually relevant in literary communication/information mobility or whether they are mere transitory symbols that have no literary communication/information where they appear in the texts. However, the terms, non-metaphorical and nonmetaphorised objects are used interchangeably.

Nwaozuzu (2007:47) observes that the most artistic or creative representation of a stage prop could remain incomprehensible if it is not organised and presented in line with the function of the potential act that defines its utility. It is when a reader of a script, or percipience of a drama performance understands the relationship between an odd concept and an artistically intentional stage prop that such a design would not be taken as a distraction or a mere work on scenic art. Therefore, the significance of this study is that it points at the need of planning in selecting dramatic objects in a play for effective literary communication. This awareness is absolutely pertinent for the understanding and appreciation of Igbo drama and its component elements. A study of this nature could encourage more related critical studies on Igbo and other African dramatic literature, especially as there are limited studies on Igbo literature as it relates to stage props. Paying attention to the study of dramatic objects and what they mean in plays could encourage audience attention to such commonly neglected elements of drama.

\section{LITERATURE REVIEW}

The views of the theatre semiotics draw attention to the position of every part of a play in ensuring performability on the stage. The term, semiotics is from the Greek word, 'Semeiotikos,' meaning the observation of signs. However, the Encarta Dictionary sees semiotics as the study of signs and symbols of all kind; what they mean, and how they relate to the things or ideas they refer to. There are different approaches to the discussion of theatre in semiotic terms. For example, there is the Prague School approach, the Kowzan school approach and the Ubersfield approach (Nikolarea, 1994). Elam (1980) and Nikolarea (1994) note that the earliest work on theatre semiotics could be traced to Czechoslovakia, through the body of books and articles produced between 1930 and 1940, by the Prague School structuralisms. Prague scholars like Zich (1931) and Bogatyrev (1938) attempted a structural and sign system analyses of the components of theatre.

The semiotics of theatre claims that theatre consists of heterogeneous but interdependent systems, none of which has special prominence. The implication of this claim is that the written text is denied dominance over the other systems that make up drama. In other words, the text is simply one of the systems that see to a dramatic presentation. Then other elements like the characters, the dramatic objects and so on form part of the dramatic system. The next claim is that the performance text is a macro sign or object whose meaning is constituted by its total effect. This claim shows that the text is subordinate to other constituents that make up a unified whole. This observation shows that all the signs in theatre (such as the objects/prop, costume and audience) are important as the makers of the meaning as well as 
communication agents of the whole (macro-sign). The third claim says that signs or objects in the theatre assume a set of values and functions in their own rights and can be infinitely changeable. The implication of this observation is that any object brought into a performance has a role it plays in the accomplishment of the performance and communication of the intended messages or information. There is also no limit to the interpretation the audience could give to an object on the stage. A non-metaphorised prop in one situation or context may not be the same in another. They are context bound. Another claim is that the stage bestows upon all bodies and objects, a signifying power that they may lack in their normal social function. This observation shows that an object on stage may mean more than what it stands for in a culture when it is outside the stage. Furthermore, there is a claim that the audience's ability to read signs adds an extra dimension of complexity to theatre. Honzl (1976) observes that audience's attention to dialogue or dramatic action may push the visual components into the background. This observation showcases the relevance in the study of some commonly neglected parts of a drama or play like the theatrical objects or property. Many audiences see them as mere articles on the stage without trying to call attention to what they signify or stand for in each context and content. As a matter of fact, the summary of the theatre semioticians of the Prague school is that every part of the drama text is an important part of a complex whole. The negligence of a part is capable of distorting the efficiency of the whole or other relevant parts. De man (1989) states that unnatural or manmade objects must be situated within a clear dramatic context and given sufficient vignette to attain that instant totality presence and effective meaning in a play. Morley (1992) adds that writers of the script should insert the objects used in making a play into their socio-historical conditions of existence. De man and Morley's observations imply that a writer's choice of intentional props on the stage is not carelessly done. A good writer considers the objects that are familiar to the society and level of people s/he is writing for. So, a writer's selection of stage prop should be conditioned by the culture and social level of the people that will form his/her audience. If one should be successful when putting on a show in the theatre, then that person ought to pay heed to the actors, a strong script and the prop. Without dramatic objects, the impact of a play would be lessened. This observation is in line with the views of the theatre semioticians who see the need of paying heed to everything that comes into a drama for they all work together to make the complex whole called drama.

Lakoff (1992) on his part captures the distinction between what could be seen as the metaphorical and the nonmetaphorical. Lakoff does not believe that all metaphors work with literal/figurative distinction. He posits that though much of our conceptual system is metaphorical, yet a significant part of it is non metaphorical. Using some examples like 'the balloon went up' and 'the cat is on the table,' Lakoff points out that there is nothing metaphorical in the examples. He, however, notes that as soon as one gets away from concrete physical experience and gets to talk about abstractions or emotions, metaphorical understanding becomes the norm. So, for Lakoff, the conceptual system of a literary work could consist of the metaphorical and the non metaphorical. Yet, the two are not clearly unconnected to each other.

Lasswell (1948) on effective communication posits that the main essence of communication is to exchange or impart ideas, knowledge, or information. Drawing from the second world war experience, Lasswell puts up five components or stages of communication; the source (who says), the message (what was said), the medium (in which channel), the audience (to whom was the message intended for), then the desired intention (to what effect). Lasswell observes three vital elements for all interactions or communications:

i. The use of language; this is because the understanding of the message could be conditioned by language clarity.

ii. Behaviour; he believes that one on one contact could also affect the meaning of communication.

iii. The use of symbols; Lasswell reasons that getting across a message could be complex because a message could be misunderstood, misinterpreted and ignored. Hence, he suggests a careful thought and selection of symbols (physical or non physical) when delivering intended messages.

The implication of Lasswell's viewpoint on communication, in relation to literature, is that the literary artist (the source) has something to say to an audience. That thing has to be said through a medium, physical or otherwise or even both. Then, the medium is deliberately selected to suit the type of message intended. Holland (1978) studies the Brechtian plays. In the plays, he observes that the strength of the presence of objects on stage is a key motive in Brechtianism. He also says that Brechtian plays are known for solid selected objects like the 'twin gate' in the play titled, The Caucasian Chalk Circle. Grebanier's (1979) study of the physical objects in Albee's The Zoo Story, argues that there are stage objects that mean more than mere objects in plays. Objects of such nature can communicate something clearly as characters on the stage can do. He observes that a knife in a drama text is made active by the dramatic activities revolving around it. It is made to transcend its existence as ordinary prop by its being animated.

Losnedahl (1992) tries to find out what stage props convey about the art of acting. His analysis is based on the props used by the dramatic society in Bergen of Norway. His discourse is mainly on two stage props used by a group of amateurs in this society. The props are pudding and a cheese made of pasteboard. These props were used in 1794 and rediscovered in 1985 with other painted props used. Losnedahl (1992) sees the styles of the props, that is, the shapes and colours as resembling the objects they represent. So, he says that they might point to realism. He notes that the intention of the makers may not have been to make them identical with reality but realistic props and low realism props elicit equal amount of group dramatic play. The props studied are not paintings but independent artifacts standing by themselves. He claims that the shape, colours and style of the props might point to realism because of the resemblance between the items and the genuine objects they are icons of. The props are not to be mistaken for real foods and cannot 
be eaten. However, he points out that the intention of the makers of the props may never have been to make them identical with reality, but rather to create feelings of recognition by informing the audience about the environment and supporting the actor in giving him/her a milieu. He comments that the props could be used as sources to understand the art of an action. At the same time, he points out that the observed functions do not put props on top of the functional hierarchy of elements on stage. In any case, he says that props give the context of the art and help to support the actor. Losenedahl (1992) also observes that 'drama objects on the stage bring the actor and acting into focus of attention.' Brandt and Grunnet (2014) examine drama and props in user-centered design. They apply the Scandinavian participatory design tradition to experiment the use of drama and various props as approaches used in engaging users directly in the design process. The study observes that props are not only 'things to think with', but are also 'things to act with' during a collaborative design process.

The appraisal tools used for this study are three Igbo plays written by A. B. Chukuezi. The method of analysis adopted for the study is the 'Content Analytical Method.' This method is otherwise known as the textual analytical method. It is a method for studying the content of recorded or documented human communication like books, et cetera. This method is preferred in this study because it is the method that allows a researcher to look into a larger amount of textual information in order to identify the properties of the text systematically. It is the method that addresses questions like which?, who?, what?, how?, why?; and to what effect? The aspects of this method that will guide the reader is the area that addresses the questions such as, what and what are the objects concerned?; why such objects?; and what effects do they have in the context where they are used?

\section{NON-METAPHORISED OBJECTS IN THE STUDIED TEXTS}

The steps to be followed under this heading include: first, the stating of an object or group of objects. Second, the identification of the type of object each is considered to be, then, the discussion of the relevance, role, or position of the identified object in each context.

Objects 1, 2 \& 3: Oku (fire), Oka (corn), and Ube (pear). The three objects are all from Udo ka mma (p.2).

Type of objects: These objects are seen as non-metaphorical character sustaining and scene illuminating devices.

Relevance: The utility of these objects is seen in their ability to keep characters busy on the stage. Thus, the objects as scene sustenance devices serve in sustaining some characters on the stage. The roasting of corn and pear by Ujo and Ihegwu in $U d o \mathrm{Ka} M m a$ (p.2) keeps the stage and the characters on the stage lively. Action is an important element of drama. Again, these objects throw light on the time setting of the play. The fire place, where people are warming themselves could be telling the atmospheric condition of a cold weather. The roasting of the corn and the pear communicates the season; the raining season when crops like corn and pear are grown and harvested. Thus, a common practice during the rainy season in a typical African Igbo traditional society is the roasting of corn and pear that goes with it while people sit around a fire place to warm themselves up. So, some cultural practices of the Igbo are revealed or communicated through the actions around these stage props/objects. Through these objects, the theme of communalism in the traditional Igbo cultural setting is also communicated. The act of a friend being so free to visit a friend early in the morning and at the same time, shares what the friend has shows the spirit of communalism and hospitality in the culture where the play is set.

Object 4: Anwuru (snuff/tobacco). This is a hand prop seen in Udo ka mma (pp. 2, 29, 42, 47) and also seen in Aku fechaa (p.1).

Type of object: In each of the two plays where this object is used, it takes the position of a non- metaphorical character sustenance device and time filling object. It is most likely that this object has been employed in each case to sustain characters on the stage before other characters or actions are introduced. The act of taking in the snuff in each case with all the peripheries or flamboyances that go with it sustains the characters that use them on the stage in the various texts.

Relevance: The use of the object makes the scenes lively and active where it comes in. The sneezing induced by the snuff adds colour to the performance. It also communicates a cultural habit of the Igbo people where the plays are set. The snuff could have been deliberately used to show what can substitute for kola or go with kola among the elderly Igbo people. However, the presentation of the snuff brings out the theme of hospitality contained in the play. An Igbo man will want to present something he eats and can afford to his visitor. That is why an Igbo adage says $o$ bu ebe aka ruru onye mkpumkpu ka o na-ekobe akpa ya meaning, it is what one can afford that one gives.

Object 5: Nri (food). It is an object in Udo ka mma (p.7) and Akwa nwa (p.1).

Type of object: The position of $n r i$ as a dramatic object in the two plays could be viewed differently. In Udo ka mma, $n r i$ as an object could be viewed as a scene and character sustaining device. The pounding of food keeps Obidiya active on the stage. However, in Akwa nwa, nri could be seen as a conflict trigger device and indicator or message conveyance device. One can say then that the yam to pound ( $r$ ri ji) is a planned dramatic object employed intentionally to stir up the actions that followed and to reveal some likely major intended themes in the text.

Relevance: While it can be said that ' $n r i$ ' in Udo ka mma makes the scene lively before another character joins for further actions, its role differs in Akwa nwa. In Akwa nwa, nri stirs up actions. It is the instrument that exposes the relationship between Chimma and her husband's family, especially the resentment she faces as a result of childlessness. Chimma tries to perform her role as a wife by preparing food for her husband. Instead of appreciating her effort, she is 
reminded of another role she could not perform as a mother. It is the necessity to help pound the yam ( $n r i$ ji) that attracts the child who comes to help out. Then, quarrels ensued from the help. So, one can argue that food (nri) is an active instrument or object that the writer uses to trigger off a major dramatic conflict in Akwa nwa. The conflict, actions or arguments following the food's ( African society. Above all, major themes such as hostility, marginalisation, childlessness, resentment, survival of the fittest, antagonism, communalism and man's inhumanity to man are ushered in by the preparation of this particular object ( $n r i$ ji). This can be summarised thus: food ( ri ji) as a dramatic object is relevant in its context for it attracts the need to pound the yam. That need attracts help, the help attracts quarrels or dramatic conflict, then the conflict brings out the above mentioned themes. This could be put in a sketch like this:

Yam to pound (i.e.food) $\Longrightarrow$ need to pound $\Longrightarrow$ help $\Longrightarrow$ conflict $\Longrightarrow$ themes

Another important role of food nri as a dramatic object in Akwa nwa and Udo ka mma is that it is used as a means through which the expected role of a woman in Africa is communicated. Chimma in Akwa nwa and Obidiya in Udo ka $m m a$ are both seen trying to perform their roles as wives by preparing food ( $\mathrm{rri}$ ) for their husbands, showing that it is merely the role of a woman to cook food in a cultural African setting.

Objects 6: Ihe ndi e ji esi nri na afere (cooking ingredients and utensils): these are objects in Udo ka mma (p. 7)

Type of objects: Non-metaphorical message conveyance devices

Relevance: These objects throw light on the place or type of scene presented. They show that the scene is set around a kitchen environment.

Object 7: Mmanya (wine). It is used in Udo ka mma (pp. 18, 29, 42, 54, 56, 82, 88, 90), Akwa nwa (pp.14 \& 70), Aku fechaa (pp. 4 \& 55)

Type of object: Non-metaphorical theme revealing, illuminating, plot extension and scene sustenance device.

Relevance/role: Wine mmanya as an object in the three plays performs different duties. In Udo ka mma, it could be seen as a theme revealing device where Akunna and his kinsmen are seen in Maduka's house with pots of wine. In a typical Igbo society, when kegs of wine are presented to a family, issues of marriage, condolence, solidarity, felicitation, extension of hand for friendship, apology and reconciliation are not usually far from the situation. So, to see men carrying kegs of wine to another man's house, especially when there is a maiden there, the issue of marriage will be suspected first before any other thing. When Akụnna and his kinsmen declared their intention on Ego, Madụka's daughter, it becomes a re-iteration of what the kegs of wine suggest. The same is the case when Dike and Ekwekwe, his friend tried their luck in asking Ego's hand in marriage. The keg of wine they went with could be looked at as a suspense creation device. The audience will likely wonder if they have come to ask for apology since there is a long lasting enmity between Dike's father and Maduka. The next question is if it could be for marriage since the audience is already aware of the secret love affair between Dike and Ego. The audience will again be eager to see how Maduka will react when the intention of their coming to his house with a keg of wine is made known and especially when it is from a strong enemy's son. Ekwekwe told Maduka that they have come with wine: 'o nwere ntakiri mmanya anyi buru bịa... anyi amaghi ihe i ga-ekwu ma o buru na i hughi anyi na udu mmanya...' (there is a little quantity of wine we have come with. We do not know what you will say if you do not see us with a pot of wine). This speech made by Ekwekwe shows that a keg of wine in the Igbo culture communicates something. As they mentioned and presented the keg of wine in order to declare their intention, Maduka readily showed his understanding of what Ekwekwe meant especially by the line of action he took after this declaration. The main point here is that the keg of wine in this scene reveals the theme of interest; it could be interest in 'reconciliation, peace, extension of hand for friendship or even marriage,' after a long time of war between Obiekwe and Maduka's people. The theme of 'rejection' comes in here with this same object. That is as Maduka drives Dike and Ekwekwe, along with their wine, away from his house. In Igbo culture, the rejection of a person's wine is an outright rejection of that person and the person's request or intent. The rejection of the wine in this scene also reveals the theme of 'bitterness.' There is great bitterness between Ụmụobịa and Ndịkpa people. In page (82) of Udo ka mma, there is still the evidence of the use of wine to bring out the theme of peace, reconciliation, and even marriage. 'Otutu udu mmanya' many kegs of wine could tell anyone that the visit to Maduka's house was not for child's play. Many kegs of wine could mean that many things could be involved especially something like marriage. The discussions within the visitation prove that the visitation with wine is for reconciliation, peace, and marriage.

Another important use of wine in the Igbo cultural setting is revealed on page (56) of Udo ka mma. Wine is culturally used in festivities and merriments as can be seen in the above stated page. In this very scene, wine is used as a plot extension and conflict initiation device. The drinking and sharing of the wine in this scene bring a big quarrel which leads to a fight between Iwueke and Osuagwụ. Iwueke claims that he is being marginalised in the sharing of the wine used for the ceremony in Uchenna's house. The conflict caused by the wine extends the plot to its climax; the point that could be called the last and the hottest battle between the two enemy communities; Ndịkpa and Ụmụọia. So, the object, wine 'mmanya' could have been intentionally employed to bring the conflict in the play to its climax. It is a point where the tragic aspect of the play is made manifest. Here is a report from a character in the play: "Ochi agha....ha egbuola Okorie....' (Commander.... they have killed Okorie). The object, 'wine' sets the fire that extends the already dreaded war to its peak. 
In Akwa nwa, wine mmanya is also used as an action sustenance device during the ritual of purification carried out in order to cleanse Akujuobi for driving away his wife in pregnancy. The act of pouring wine on the ground while reciting the purification incantation adds life to the action or performance on the stage. The act of pouring wine on the ground also reveals an aspect of Igbo cultural belief, that is, the belief on gods of the earth that must be pacified before any ritual could go through. Wine mmanya, in Akwa nwa is also seen as illumination or message delivery vehicle. In page (14) of the same text, Eke presents a gourd of wine to Onụoha who refuses the offer. The refusal of the wine triggers off an argument. Through that argument, one may conclude that the wine and the gourd are designed objects in this play used to teach or talk about hygiene and maintenance of health. In Onụoha's words: '...ihe mmuta nke m so n'ime ya naegosi na o dighi mma mmadu abuo iji otu mpi na-añu mmaị. O na-ebufe orịa dị iche iche' ('...the knowledge I have acquired shows that it is not good for two people to drink with one gourd. It brings about the spread of different types of diseases').

The presentation of the objects (the gourd and wine) also reveals a time setting of culture conflict; that is, a time when the traditional way of life is conflicting with new ideas and beliefs. The dialogue between Eke and Ọụọa below exemplifies this.

Eke: ...tupu nna gị a mụo gị mpi a ka anyị ji aṇu mmaị ... (... before your father gave birth to you, we were drinking with this gourd...)

Ọnụọha: Ọ bụghị iwe. Ọ bụ maka ndụ ka e ji asọkwanụ ihe ndị a (It is not out of annoyance but it is to preserve life that one is careful).

The refusal of the wine and the gourd; along with the arguments following seems to have been deliberately employed to communicate some themes in the play such as the theme of hygiene, culture conflict and respect. Onuoha shows that in teaching the new way of life, respect should be maintained thus he said, "iwe adila gị n'obi nna anyị" (Do not be angry father). The wine and gourd trigger the argument about the manner in which the object is presented. The argument in turn ushers in the intended message about hygiene, culture conflict and respect.

In Aku fechaa, wine mmanya (palm wine:p. 4) can also be viewed as another information delivery device. Agu poured wine in a gourd, tasted it first, before giving the wine to Ụọ. This passes the message that there may have been the culture of poisoning or distrust in the culture of the place the play is set. So, the presenter of the wine ensures transparency and honesty to his visitor so that fears of any kind will be allayed. Above all, this act of wine presentation and drinking on the stage sustains the scene actively.

In page 55 of $A k u$ fechaa, the device of using wine to sustain a scene while at the same time illuminating some ideas is evidenced. Igwe Akukarịa employs a cup of wine to offer prayers. The prayers offered sustain the scene. At the same time, it throws some light on the prayer mode and beliefs of the Igbo culture where the play is set. When the cup of wine is raised, the prayers that follow reveal some common beliefs and sayings, example, "okuko nwa ogbenye bu ewu $y a$..." (A poor man's fowl is his goat). The various sayings that follow the raising of the cup tell a lot on the themes of the play; first is the theme of contentment in life. Another one is the theme that man is insatiable by nature. When Igwe Akụkaria throws away the cup of wine after Odumodu's address, this shows that the festivity that started cannot go on.

Object 8: $M m a$ (matchet). As a dramatic object 'mma' is also used to achieve some dramatic effects in the plays under study.

Type of object: For instance, matchet mma in Akwa nwa (pp. 23 \& 24, Act 1 scene 3) could be seen as a nonmetaphorical revelation or expository instrument. Knife mma in Udo ka mma (pp. 44 \& 76) is also seen as a mood exposition device. In Akwa nwa (p.71), 'mma' is a plot extension device.

Relevance: It is the object that reveals or exposes the degree of Akujuobi's anger and resentment for Dr. Onụọha and his wife, Chimma in Akwa nwa. Anyone who sees such in his hand understands immediately that all is not well when a man carries a knife in anger. One can then say that the writer of the play, Akwa nwa might have used that instrument to convey the degree of a character's anger. One can be angry without carrying a knife, but when an Igbo man is angry to the extent of carrying a matchet, one will know that the anger is a serious one. That is why Eke asks, as he enters Akujuobi's house and sees him flinging a matchet before Onuoha; "Igwe, o dịkwa mma? Gịni na-ese? (Dear king, is all well? what is the problem?) "Nke igwe bu mma, O bu gini mere?" (This one the king is carrying a knife, what happened?).

In Udo ka mma, the act of Maduka bringing a knife to pursue Dike and Ekwekwe from his house shows the extent he is offended by their visit. Their visit is seen as a serious insult to Madụka especially when such a visit is coming from his enemies. Thus, Madụka expresses his disapproval via the knife he uses to drive the visitors out of his house. In the same manner, Obiekwe tries to express the extent of his anger to his son, Dike, by going after his knife: 'o bilie $n$ 'iwe choo mma ya...'(p.76) (he gets up in anger and searches for his knife). This is as Dike reveals his trip to Maduka's house, knowing fully well that Maduka is Obiekwe's greatest enemy. So, the knife in these scenes could be said to serve as objects used to project the level of anger in characters that used them in the play. However, it is not totally strange to see an Igbo man carry a knife when really angry just as a white man can easily carry a pistol when angry so as to deal with a person who annoys or hurts him seriously.

In Akwa nwa, the knife is used to resolve the conflicts. It is the object Akujuobi used to kill the sacrificial animal whose blood is used to cleanse his offences. Without the killing of the animal, to shed blood, the problem created remains. The knife is used to bring the sanctification ritual to reality. The stage of reconciliation comes in here. So, all 
the paraphernalia with the knife do not only sustain the action but also extend the plot to the end of the scene of sacrifice. There is a similar case in Aku Fechaa (p.23) where knife mma features as 'action sustenance device'. The knife in Agụ's hand while in the bush keeps him active in the bush. He uses it to clear the bush and keeps himself busy on the stage. The use of the knife, in one way or the other in that scene makes the scene to remain lively and sustains the character to remain active.

Object 9: Akwukwo nri (green vegetable; Udo ka mma, p. 47)

Type of object: Non-metaphorical character sustenance and plot extension device.

Relevance: The green vegetable sustains Ego on the stage and scene. It could be interpreted as a deliberate device to retain and occupy Ego on the stage and at the scene where Maduka, her father discusses Dike with his friend Umụnnakwe. Her presence on the scene gives her the opportunity to make the audience hear her opinion and see her stand in the whole case. She said, 'hapunu Dike, kedu ihe o mere unu ugbua? O bu ya bu Obiekwe? (Leave Dike alone, what has he done to you now? Is he Obiekwe?) This interruption from Ego aggravates Madụka's anger and he reprimands her. All these contribute in making that scene active. Above all, the argument raised reveals some major themes in the literary work like the theme that 'love knows no boundary.' Ego voices out her determination to marry Dike no matter whose ox is gored.

Object 10: 'Akpa nta, Okpukpu isi anu dị iche iche, opi enyi' (Hunting bag, different types of animal skulls, elephant tusk; Aku fechaa, p.15).

Type of objects: Non-metaphorical information and character identification agents.

Relevance: The above mentioned objects tell a lot about characters within the scene. The scene eventually features Agụ as a hunter. A hunter's environment cannot be totally disassociated with the kinds of objects listed above. More so, they give clues on the hunter's prowess. The implication is that Agụ is a strong hunter who had been able to kill a lot of animals as the skulls and the tusk show evidence.

Object 11: Bingo (a dog); Aku fechaa (pp.16 \& 23).

Type of Object: Non- metaphorical clue giving device.

Relevance: Traditional Igbo hunters usually go with dogs. It is believed that dogs are good at perceiving what a person may not easily perceive; so, the presence of a dog in Agụ's life projects one of the major instruments used in a hunting job in a traditional Igbo society.

Object 12: Egbe (gun); Aku fechaa (pp.23- 24).

Type of object: Non-metaphorical clue giving device or illuminating device.

Relevance: Agụ's struggle to remove his gun from his shoulder and the inability to do so shows that something serious is taking place. A hunter's gun is part of him. He has the mastery of it in times of trouble. Now, the disagreement between the object and the character could imply that something strange and extraordinary is about to happen or is happening already.

In page 69 of the same text, gun egbe, as a dramatic object could be interpreted as sustenance and character identification device. The gun and attending to the gun sustain the character, Obi, on the stage before Egodiya came in with her problem. One can also deduce Obi to be a hunter by his engagement with or attendance to the gun. In a typical Igbo traditional society, hunters could be identified with the hunter's gun. Above all, the gun, in each case, keeps a character busy till another character joins the stage.

Object 13: Oja (local flute); Aku fechaa (p.53).

Type of object: This can be seen as a non metaphorical scene extension and mood changing device.

Relevance: The playing of the local flute oja, as Igwe Akukaria steps into the scene extends the scene's action. The dance on the stage is intensified as the oja sounds. A title holder steps out to sing praises unto the king who steps in with dignity and gentle dance steps. The celebration mood of the scene is intensified when the flute goes thus; 'otu onu opi wee daa, igwe... na ndi odibo ya gara bata n'ugwu, ndị egwu wee bido egwu ozo...' (As the flute goes, the king and his servants step in, the music started again....)

Object 14: Ogene (gong); Aku fechaa (pp.79, 80, 82, 83, \& 84).

Type of object: Non-metahporical scene sustenance and communication device.

Relevance: It is relevant in creating sound effect for the tensed situation each time it is used on the stage. Above all, it reveals a way of tapping at the remarkable door of the spirits when trying to consult them. When it is sounded, everyone becomes expectant. For example, "ogene wee daa ozo. Anya wee to mmadu niile n'ama...." (The gong sounded again and everyone's gaze remains focused on the entrance way...).

\section{SUMMARY OF THE FINDINGS}

Going by the analyses so far on the dramatic objects identified in the study texts, we can say that the objects studied are mainly non-metaphorical in the sense that they are not used as symbolic or figurative objects with deep semantic connotations or undertones. The objects are mostly used in their literal or primary sense in as much as they contribute to the realisation of the intent of the texts. They do not connote deep structures. The dramatic objects are of different types and functioned in different capacities. Some of the objects are seen as mere plot developers, communication modifiers, plot extension devices, or objects for enhancing the visual component of the plays. For example, the object, wine mmanya, is used as a non metaphorical object in page (56) of Udo ka mma. In this very text, wine is used as a plot 
extension and conflict initiation device. The drinking and sharing of wine in Uchenna's house bring a big quarrel and consequently a fight between Iwueke and Osuagwụ. Iwueke claims that he is being marginalised in the sharing of the wine used for the child dedication ceremony in Uchenna's house. The conflict initiated by the object, the wine mmanya could be said to have been intentionally employed to extend the plot to its climax; the point that could be called the last and the hottest battle between the two enemy communities; Ndịkpa and Umụọbia. It is a point where the tragic aspect of the play is made manifest.

The functions of the dramatic objects as seen in the study show that the objects can also work in the capacity of theme, mood, and character illuminators. Using the case of ' $n r i$ ji' in Akwa Nwa (pg. 1) as an example, the object triggers off a conflict between Chimma and Ihudiya because the latter's daughter is seen helping the former in the preparation of the nri ji. The quarrel that ensues from this incidence, initiated by the cooking of the food ( $n r i j i)$ throws light on some themes about polygamy in a cultural Igbo African society. Such themes as have been discussed already include hostility, marginalisation, childlessness, resentment, polygamy, survival of the fittest and antagonism. There are other similar examples as shown in the analyses. As mood and character illuminators, the object, mma (knife) could be used as a typical example. In Akwa nwa for instance, (pp. $23 \& 24$, Act 1 scene 3), the act of taking up the object reveals or exposes the degree of Akujuobi's anger and resentment for Dr. Onụọha, whom he is suspicious of having an affair with his wife, Chimma. Again, in Udo ka mma (pp.44 \& 76), Madụka expresses his disapproval of Dike and Ekwekwe's visit to his house in order to ask for the hand of his daughter in marriage via the knife he uses to drive them out of his house. One can then say that the writer of the plays, Akwa nwa and Udo ka mma might have used that instrument to convey the degree of his selected characters' mood (of anger) and character trait; short temperedness.

Again, the use of some dramatic objects to initiate plot extension, communicate some themes, and mood, as have been discussed above, points to the fact that there could be some relationship between the dramatic objects in a play and other dramatic elements in the same play. So, one can claim that non-metaphorical dramatic objects can be part of the system that helps in the full realisation of dramatic effects in Igbo plays. They can be important in the modification of meanings since they have been shown as communication agents in the present study.

It also observed that a stage can bestow upon an object, a signifying power that the object may lack in its normal social function or status. That is to say that what an object means or stands for on the stage may not be what it stands for outside the stage or a text. Example is the object 7: 'Mmanya' (Wine) as evidenced in Udo ka mma (pp. 18, 29, 42, 54, 56, 82, 88, 90), Akwa nwa (pp. 14 \& 70) and Aku fechaa (pp. 4 \& 55). Outside the scenes where this object is used, mmanya in the traditional Igbo society could be looked at as an alcoholic drink that can be intoxicating or stimulating, used in social gatherings or even for individual purposes. However, in the scenes where it has been used as a dramatic object as identified above, it has been interpreted as non--metaphorical theme revealing, illuminating, plot extension, and scene sustenance device. Mmanya (wine) as an object in the three plays performs different duties. In $U d o$ ka mma (p.56) for instance, it could be seen as a plot extension, conflict initiation and theme revealing device. Here, 'mmanya' as an object initiates the fight between two enemy parties; Maduka's people and Obiekwe's people in Iwueke's house. The fight, induced by the 'mmanya' as an object, brings the storyline to its climax as blood was shed. In this order, the theme of war is revealed. The issue induced by this same object also qualifies the text as a tragic comedy. In $A k w a n w a$ (p.14), we can interpret the same object as an illuminating or message delivery vehicle. The evidence is in the scene where Eke presents the object (mmanya) to Onụọa; a modern day medical doctor; in a gourd from where Eke himself had drank from. Onụoha's refusal to drink from the same gourd triggers off some arguments about the culture of the land and what the modern science is saying. Through this development, some possible intended messages or themes are passed on. Such messages are; the importance of personal hygiene, the consequences of unhealthy cultural practices, the problem of culture conflict and respect for elders. It is worthy to note that the writer of this play is a seasoned medical doctor who understands the above discussion and may want to relay the message of healthy medical practices to his audience. The study shown that context identifies and defines an object. The same object may not mean the same thing in a different environment.

\section{CONCLUSION}

So far, we have explored some stage props/objects used in three Igbo plays. We have particularly looked at them as non-metaphorical objects suspected to have been intentionally used in the drama texts or on the stage to influence or connect the audience or the percipients. Looking at the texts analysed, it could be seen that the creation and selection of dramatic objects or property in a play could be said to be a major artistic endeavour. It involves a lot of imagination, research, knowledge of the culture in which the play is set, knowledge of the content and context of the theme being handled. Hence, the need to pay very good attention to issues concerning theatrical property cannot be overemphasised.

Our study has shown that great actors or strong scripts are not the only factors that ensure the success of a play. Carefully selected theatre props or objects can garnish a piece of play to an excellent taste. Our study has also shown some important positions dramatic objects can occupy in plays. From the texts studied, we have seen that props or dramatic objects could either be influencing or connecting the audience or percipients to a writer or a text's intent, message, revelation, direction, views, opinions, etc. Again, the study has shown that what the actor could mean with his/her selected dramatic objects or property depends on the culture and the era (i.e. time in history and the beliefs and practices obtainable then.) For example, yam, as a prop in Akwa nwa is a major cultural food among the Igbo where the 
play is set. Palm wine, as another prop in the same text, is a cultural drink of the Igbo. Then, the gourd as an object ushers in the condemnation of sharing one gourd or drinking from one gourd. This object gives time setting information. It informs that the text was set at a time when new hygienic measures are advocated against the old norms and values. So, the gourd could be seen as a carefully selected object to generate a healthy argument. The argument surrounding the object passes across a message that is needed at the set time. The above examples show that whatever the text achieves on the stage depends on the interaction and mode of interaction created. The creation of well thought out stage props is a powerful mode of interaction in a drama text. Another finding in this study is that a theatrical object or prop in a play is usually employed with one or more intents within a given social community or context.

Another fact is that a stage property could be interpreted within the context of use. This observation could mean that a prop's implication in a play or a given context of a play may be different from what it means ordinarily (i.e. outside the given drama context.) For example, ' $n r i$ ji' in page one of Akwa nwa ordinarily means food for the traditional Igbo society. However, in the drama context where it is employed, it could be seen as a conflict rolling instrument between two characters in the play. The need to pound the yam attracts Nkeiru to come and help. The help aggravates her mother's anger which in turn leads to quarrels between Chimma who is helped and Ihudiya, who is Nkeiru's mother and Chimma's co-wife. Yam, in this context can also be seen as an instrument for communicating the social level of the family being introduced in that scene. Yam, in Igbo culture is a prestigious crop. Though yam could be ordinarily eaten with oil, sauce, or as porridge or pepper soup, it is not always pounded in every home except in the homes of those who can easily foot the bill. So pounding yam as an ordinary meal in Akujuobi's family tells of his social class.

Another observation made in this study is that it may not be easy to have a clear cut division between the metaphorised and non-metaphorised intentional props. An object seen as non-metaphorised by a critic could be interpreted as metaphorised by another literary critic from a different cultural setting, especially by implication. If we go by the claim of the Deconstructionist criticism, literary texts have no fixed single meaning. The deconstructionists hold that it is impossible to make a sign coincide with what is signified. In other words, there is no limit to the interpretation of a prop on the stage. Therefore, the issue of metaphorised or non-metaphorised props may need to be revisited and redefined. There is need to establish the level of a prop's interpretation on the stage before it could be termed as metaphorised or non-metaphorised in any context.

Finally, the intentional dramatic objects, studied as non-metaphorical objects in the texts used give credence to the claim of the theatre semioticians of the Prague school which says that every part of the drama text is an important part of a complex whole. The relevance of dramatic objects or stage props in explicating and illustrating themes, characters, and settings of the plays cannot be ignored. Understanding the positions of the objects where they are used in a text may not only enhance the understanding of the language of the text but the themes, characters, settings and other elements of the text. Apart from that, these objects enhance the visual components of the play. The objects are not mere articles on the stage. One can say then that they are among the prospective tools of connecting a text to its audience. The objects studied therefore have proved to be alternate means of communication in Chukuezi's plays where they are used, thereby showing that a text is not only communicated via language.

\section{APPENDIX. THE SYNOPSES OF THE TEXTS USED FOR THE STUDY}

\section{Udo ka mma (1974)}

This is the first drama text by Anelechi B. Chukuezi. It was published by Oxford University Press. The drama text showcased a typical land dispute in a typical Igbo cultural society. The play featured a character called Obiekwe, who was the king of Ụmụọịa and a man of Ndịkpa called Maduka. Obiekwe, being a king, planned to intimidate Maduka with his social position and take over his piece of land. Maduka adamantly refused to be intimidated and held firm to his right (the land). The dispute between the two affected a lot of other people to the extent of blood shed. However, while the dispute was on, Dike, Obiekwe's son fell head over heels in love with Ego, Maduka's daughter. The two young people obstinately refused to heed to all the warnings from their parents. They were determined to die for the love they had for each other. Their insistence on what they wanted eventually paved way for reconciliation between Obiekwe and his enemy, Maduka. Through reconciliation, the land dispute was settled and Obiekwe left the land for the rightful owner, Maduka.

Akwa nwa (1979)

This is another drama text by Anaelechi B. Chukuezi. It was published by Afrcan Universities Press in the year (1979). The text dramatized the types of painful experiences a childless woman could pass through in a typical Igbo African society. Chimma, the major character in this play suffered dejection and rejection from her husband and cowives, especially Ihudiya. Chimma had no child. Her pains became worst as she was driven away from her matrimonial home. Apart from that, she was grievously accused of infidelity. At last, the gods intervened in her case and proved her innocent. It was eventually seen that she was with her husband's pregnancy before leaving her husband's house. Chimma was at last accepted back into her husband's house.

Aku fechaa (1979)

Aku Fechaa is also a drama text written by Chukuezi and published by the University Press Limited in the year (1979). The text featured Agu, who was selected by Iyi-Mbaa deity to serve in its shrine. Agu vehemently refused this assignment. Iyi-Mbaa got angry with him and began to deal with him in different ways. Despite his ordeals, Agu 
maintained his ground. However, what was destined to happen would surely happen. After so much pain, Agu was left with no option but to yield to the social responsibility delegated to him. At this point, the whole crises in the play came to resolution.

\section{REFERENCES}

[1] Bogatyrev, P. (1938). Semiotics in folk theatre. In L. W. Matejka \& I. R. Titunik (Eds.), Semiotics of art: Prague school contributions (pp. 33-49). Cambridge: MIT Press.

[2] Brandt, E. \& Grunnet, C. (2014). Evoking the future: Drama and props in user-centered design. Malmo: The Interactive Institute.

[3] Brook, P. (1990). The empty space. London: Penguin Books.

[4] Chukuezi, A. B. (1974). Udo ka mma. Ibadan: Oxford University Press Limited.

[5] Chukuezi, A. B. (1979). Aku fechaa. Ibadan: University Press Limited.

[6] Chukuezi, A. B. (1979). Akwa nwa. Ibadan: African Universities Press.

[7] De man, P. (1989). Blindness and insight: Essays in rhetoric of contemporary criticism. London: Routledge.

[8] Elam, K. (1980). The semiotics of theatre and drama. London: Routledge.

[9] Grebanier, B. (1979). Playwriting: How to write for the theatre. New York: Harper and Row Publishers.

[10] Holland, P. (1978). Brecht, bond, gaskill and the practice of political theatre. Theatre Quarterly, 8, 24-34.

[11] Honzl, J. (1976). Dynamics of sign in the theatre. In L. Metjka \& I. R. Tituruk (Eds.), Semiotics of art: Prague school contributions. Canbridge: MIT press.

[12] Jeyifo, B. (1981). Literary drama and the search for a popular theatre in Nigeria. In Y. Ogunbiyi (Ed.), Drama and theatre in Nigeria: A critical source book. Lagos: Nigerian Magazine Publications.

[13] Lakoff, G. (1992). The contemporary theory of metaphor. In A. Ortony (Ed.), Metaphor and thought (2nd edition). Cambridge: Cambridge University Press.

[14] Lasswell, H. (1948). The structure and function of communication in society. In L. Bryson (Ed.), The communication of ideas: A series of addresses (pp. 37-51). New York: Institute for Religious and Social Studies.

[15] Losnedahl, K. G. (1992). What may stage props convey about the art of acting.In S. Barbro (Ed.), Records and images of the art of the performer (pp.77-78). Stockholm: Drottningholms Teatermuseum.

[16] Morley, D. (1992). Television audience and cultural studies. London: Routledge.

[17] Nikolarea, E. (1994). A communication model for theatre translation: Versions of Oedipus the king in English. Ph.D thesis, University of Alberta.

[18] Nwaozuzu, U. C. (2007). Beyond the second language dilemma: An excursion into alternate means of communicating meaning for English playwrights of Igbo extraction. Journal of Igbo Studies, 2, 43-48.

[19] Rasmus, M. C. (2018). The narrative functions of props: Portable communication devices in Die Hard (1998) and Die Hard 2 (1990). M. A. dissertation, Lund University.

[20] Sofer, A. (2003). The stage life of props. Michigan: University of Michigan Press.

[21] Zich, O. (1931). Aesthetics of dramatic art. Prague: Melantrich.

Chioma Magdaline Akaeze is an astute Nigerian literary scholar from Delta State, Nigeria. She lectures at the Department of Linguistics, Igbo and Other Nigerian Languages, University of Nigeria, Nsukka. To her credit, she holds B.A (Linguistics and Igbo), M.A (Igbo Oral Literature and Stylistics) and Ph.D (Igbo Literature and Stylistics), all from the University of Nigeria. Her research interests include African literature, culture and language. She also has lots of publications in Igbo and English.

Chinedu Chidiebere Ezebube was born at Fegge Onitsha, Anambra State, Nigeria. He obtained his first degree in Linguistics and Igbo studies from the University of Nigeria, Nsukka. From the same institution, he got his Masters Degree, majoring in Igbo Literature and Stylistics. Presently, he is a lecturer at the Department of Linguistics, Igbo \& Other Nigerian Languages, University of Nigeria. His research interest includes African/Igbo literature, gender and cultural studies, and sociolinguistics.

Ogechukwu Uchenna Chukwuneke was born at Onitsha, Anambra State, Nigeria. She obtained her first degree in Igbo Studies from Nnamdi Azikiwe University, Awka, Anambra State. She also obtained her Master's Degree from the same institution, majoring in Igbo Literature and Stylistics. She is currently a lecturer at the Department of Linguistics, Igbo \& Other Nigerian Languages, University of Nigeria. Her research interests include African/Igbo Literature, Literary criticism and Sociolinguistics.

Chioma Juliet Ikechukwu-Ibe was born at Emene, Enugu State, Nigeria. She obtained her first degree and Master's degree from the University of Nigeria. She is currently doing her doctorate programme at the same University. She is also a lecturer at the Department of Linguistics, Igbo \& Other Nigerian Languages, University of Nigeria. She is interested in the core areas of Linguistics via Pragmatics, Sociolinguistics and Psycholinguistics. 